\title{
Dynamic Voltage Restorer Using (PQ) Theory with LabView
}

\author{
Mahmood T. Alkhayyat ${ }^{1}$, Mohammed Y. Suliman ${ }^{2}$ Ibrahim F. Fakhraldeen ${ }^{3}$ \\ $\left\{\right.$ m.t.alkhayyat@ntu.edu.iq ${ }^{1}$, mohammed.yahya@ntu.edu.iq ${ }^{1}$,ibrahim.furat@ntu.edu.iq $\left.{ }^{3}\right\}$ \\ Department of Electrical Power Techniques Engineering, Technical Engineering College, Northern \\ Technical University, Mosul, Iraq ${ }^{1,2,3}$
}

\begin{abstract}
Power quality became very important for utilities as well as users. The cause of the power quality problem is instability (voltage, current, and frequency). Voltage sag and voltage swell are common voltage disruptions. They are caused by faults, disturbances arising in the transmission system, etc. This paper deals with the voltage instability compensation of linear sensitive loads by dynamic voltage restorer (DVR) using instantaneous power theory. The practical experiment results were obtained using the data acquisition card (DAQ) and LabView real-time software. The new design can compensate the voltage for $\pm 15 \%$ of the nominal value for the two conditions sag/swell. Also, the designed controller enhanced the response of less than $110 \%$ overshot at stalling time of less than $0.2 \mathrm{sec}$.
\end{abstract}

Keywords: Data acquisition (DAQ), Dynamic voltage restorer (DVR), Instantaneous power theory, (Sag and Swell), PI controller, Power Quality.

\section{Introduction}

Modern power systems are complex power networks where transmission or distribution networks interconnect hundreds of generating loads and thousands of loads [1]. Providing reliable and quality power supply is the main concern for the customer, but the production of the power supply is reasonably stable while the power quality can be poor in developed countries. The perfect power supply system provides its consumer with a steady sinusoidal voltage at the contracted voltage magnitude and frequency with continuous energy flow [2]. The problem power quality appears by (voltage sage/swell, voltage unbalance, flickers, harmonics, problems, and interruption). As a result of load switching, motor starting, faults, non-linear loads, lightning, etc., voltage sag/swell occurs. It has an essential impact both on loads based on microprocessors and sensitive loads [3]. Voltage sags decrease in the normal-voltage level between $10 \%$ and $90 \%$ nominal voltage (RMS) at the control frequency, for a period of 0.5 cycles to 1 minute. The increase in RMS voltage at the power frequency for durations from 0.5 cycles to 1 minute defines the voltage swell; typical magnitudes are between 1.1 and 1.8 p.u [4]. Different types of custom power devices are used to improve the voltage sag and swell on the loads, such as transformer with tap changer, constant voltage (Ferro-resonant) transformer, servo-controlled voltage stabilizer, connect a large-load to points of common-coupling, etc.[5]. Some of the disadvantages of these methods are the static transfer switch and one possible form of voltage sag mitigation. These instruments will move the load from the usual supply feeder to the alternate supply feeder within half a cycle upon identification of voltage sag [6]. In addition 
to that, there are other compensation techniques, such as (STATCOM, TCSC, SVC, and UPFC) [7]. A dynamic voltage restorer (DVR) is a FACTS (Flexible Alternating Current Transmission Systems) system that compensates for voltage sag and voltage swell that happens on transmission lines. The (DVR) is used for critical load safety (digital machines, advanced medical equipment, the web of financial transfers, elevators, etc.) From voltage-based problems with power quality [8]. DVR is a circuit made up of diodes and thyristors, which are power electronic devices. Because of its small size and effective service, it is widely used. Maintaining the voltage level in the transmission line within the specified limits is critical; Since it is overloaded conditions will cause all components connected to it to shut down. The Dynamic Voltage Regulator (DVR) is the SSSC's equivalent. While both are used to compensate for series voltage sag, their operating concepts are different. A balanced voltage is injected in series with the transmission line by the static synchronous series compensator. The DVR, on the other hand, compensates for unbalanced supply voltage between phases [9]. The load voltage is lower than the nominal value during sag. To ensure a steady voltage on the load, DVR injects the appropriate voltage into the circuit (the direction of the injected voltage is the same as the direction of the load voltage) [10]. The load voltage is higher than the nominal value during swelling. DVR injects needed voltage into the system (the direction of the injected voltages is opposite the direction of the source voltage) to sustain a steady voltage through the load [11]. The compensation techniques in dynamic voltage restorer depend mainly on the factors specified, such as DVR power ratings, different load conditions, type of voltage sag, and swell. Some loads are non-linear against the 1 hop step angle, some are susceptible to magnitude changes. Therefore, the control strategies primarily rely on the form of characteristics of the load [12]. There are three types of methods of DVR :

a- Pre_sag compensation method.

b- In _ Phase compensation method.

c- Minimum energy compensation method.

Fig 1 shows the phasor diagram of three methods. This paper will design based on the second method illustrated in Fig 1b. In this compensation procedure, the voltage injection is in phase with the utility voltage. The magnitude of the injection voltage in the in-phase correction for the specified voltage sag state is minimum as compared to the other current compensation methods. The dc-link voltage level is also lower if the form of compensation is in phase [13]. In Fig 2, the DVR configuration is shown.

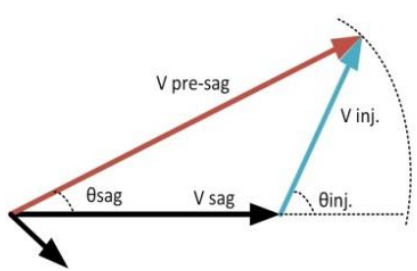

(a)

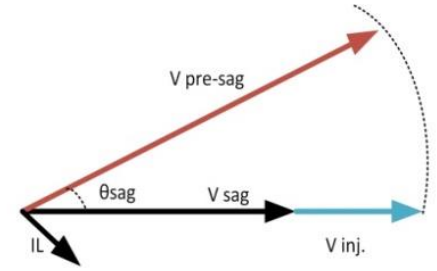

(b)

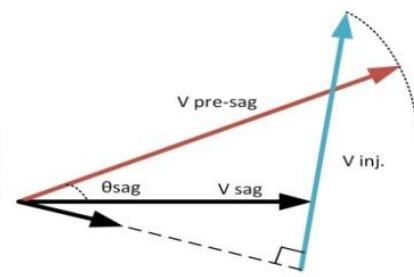

(c)

Fig 1. Phasor diagram of (a) Pre-sag compensation (b) In-phase compensation (c) Minimum energy compensation. 


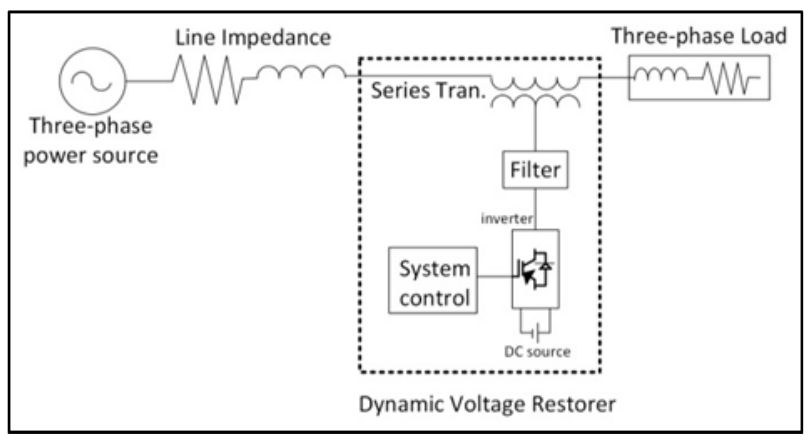

Fig 2. Schematic diagram of DVR.

Dynamic voltage restorer consists of [14] : (1-Inverter. 2-Series transformer/injection transformer. 3-Filters. 4-Control system.5- And energy storage device). Based on the voltage sag in the literature, several studies have been suggested to increase power quality. In [15], the DVR control system using adaptive neuro-fuzzy logic has been used. Takagi-Sugeno fuzzy rules are trained using an off-line neuro-fuzzy system in this controller. In [16], a DQ theory in DVR was used to detect the (sag/swell) with sinusoidal pulse width modulation (SPWM) and voltage supply inverter (VSI). The authors in [17] presented DVR using three-dimensional space vector modulation (3DSVM) and validated it by simulations in PSCAD-EMTDC software. While the authors in [18] used a proportional-integral (PI) controller for (DVR) to improve suppress voltage sag. In [19] used as a STATCOM to enhance the profile of the voltage. This paper proposed a dynamic voltage restorer (DVR) based on instantaneous power theory, with enhanced PI limiting to improve the voltage sag/swell condition that happens in the system.

\section{DVR Based (PQ) Theory}

The load voltages are calculated in this methodology based on active and reactive power components [20]. The Phase-Locked Loop (PLL) is often used to obtain the phase angle ( $\theta)$ and source voltage frequency [21]. Using the Clark transformations [22], the three-phase device voltages and three-phase load voltage in the a-b-c coordinates are translated to the $(\alpha-\beta)$ coordinates as follows:

$\left[\begin{array}{l}v \alpha \\ v \beta\end{array}\right]=\sqrt{\frac{2}{3}} \times\left[\begin{array}{ccc}1 & -1 / 2 & -1 / 2 \\ 0 & \sqrt{3} / 2 & -\sqrt{3} / 2\end{array}\right] \times\left[\begin{array}{c}v l a \\ v l b \\ v l c\end{array}\right]$

$\mathrm{V} \sum=\sqrt{v \alpha^{2}+v \beta^{2}}$

Where $\left(\mathrm{V} \sum\right.$ ) is the (RMS) aggregate voltage. The aggregate voltage is compared with the desired voltage to generate error signals $(\Delta \mathrm{V})$. This signal is processed in the PI controller [23]:

$\mathrm{U}=\mathrm{Kp}+\mathrm{Ki} \int e d t$

$\mathrm{E}_{\Delta v}=\left(V_{\text {ref. }}-V_{\Sigma}\right)\left(K p+\frac{K i}{s}\right)$ 
Where, E $\Delta \mathrm{v}$ (voltage to generate error signal), Vref ( reference voltage), Kp (proportional gain), $\mathrm{Ki}$ ( integral gain).

Fig 4 Show the (PQ) theory of Dynamic voltage restorer (DVR).

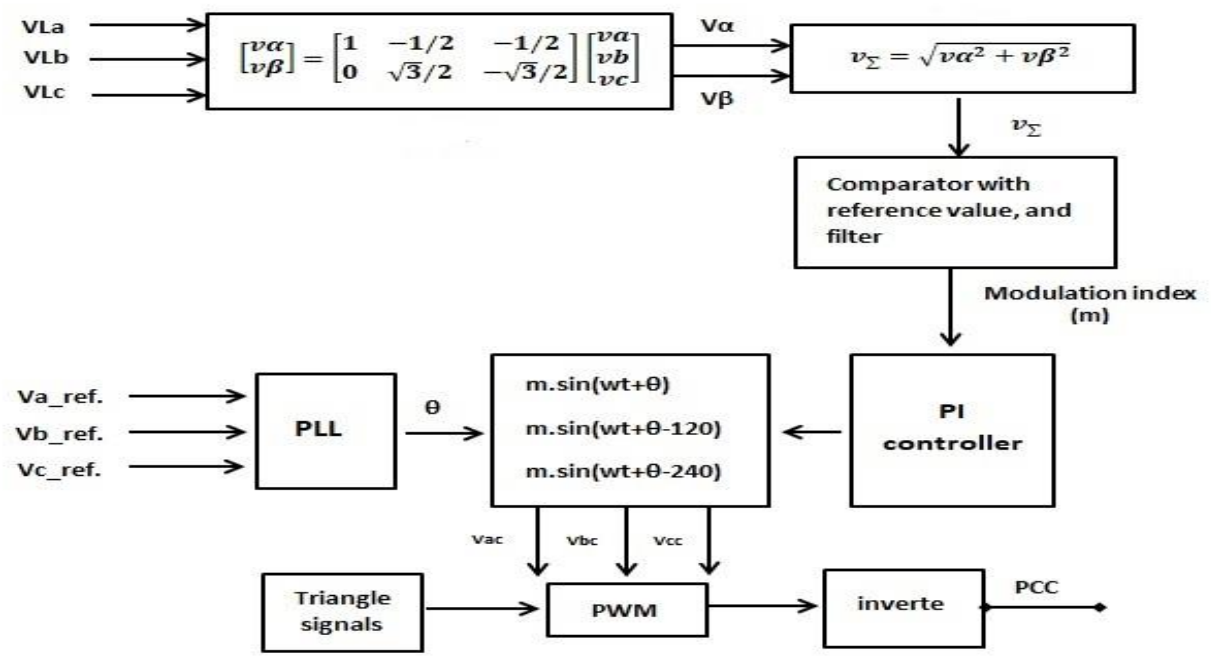

Fig 4. Dynamic voltage restorer-based PQ theory

\section{Prototype and Experiment Results}

DVR is designed in the laboratory to compensate for the (Sag / Swell) problems. The design was considered to verify the DVR based on (PQ) theory. The model is shown in Fig 5.

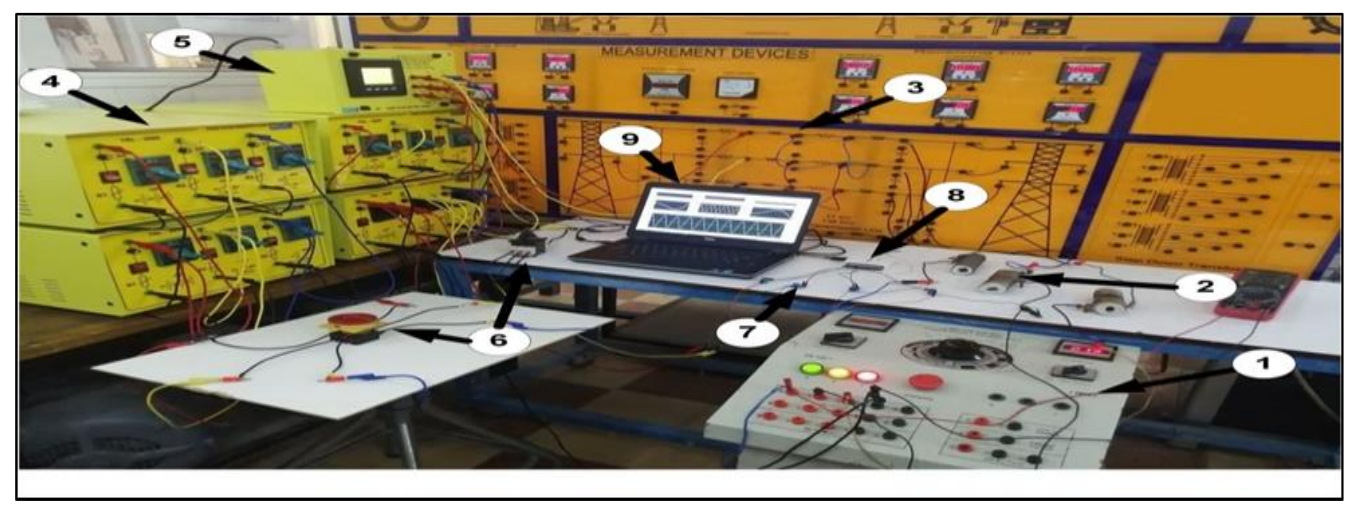

Fig 5. DVR prototype. 
The DVR model is comprised of: (1- Three-phase source: It is a device that equips a working circuit with a three-phase voltage balanced by a fixed phase difference between the phases of 120 degrees. 2- Resistances in the transmission line. 3- Inductive in the transmission line. 4Three-phase loads. 5- Three-phase electric meter. 6- Three-phase switches: for add /remove loads on the sensitive loads. 7-Voltage sensors. 8-Data Acquisition card. 9-Laptop).

The proposed model was verified by applying (PQ) theory using LabView software [24]. The results were acquired in real-time by the control card (DAQ). Block diagram of (PQ) theory for Dynamic voltage restorer (DVR) in LabView is shown in Fig 6.

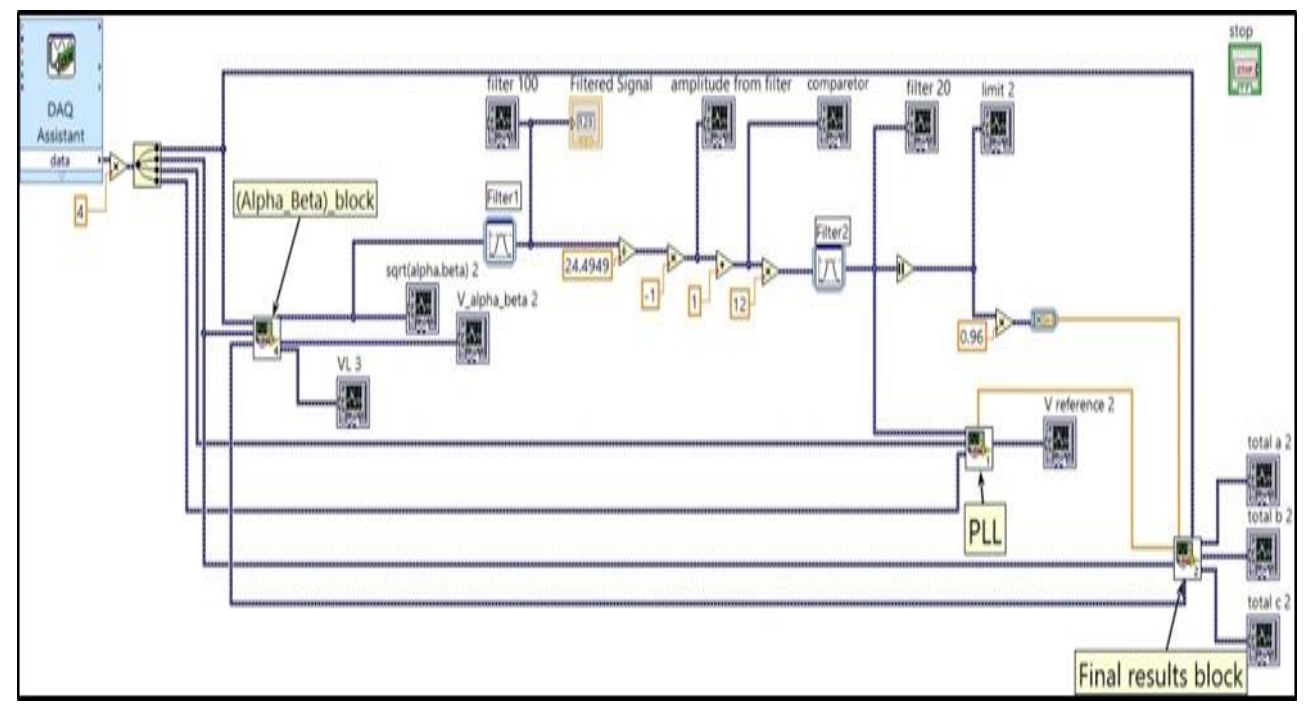

Fig 6. Schematic block diagram of (DVR) based (PQ) theory.

Fig 7a Shows a block diagram of the Clark transformation. It's the first part of the PQ theory using LabView. The phase-locked loop (PLL) design by LabView to synchronize the injected voltage with the system is shown the Fig 7b. The block diagram of the output of PQ theory (modulation index) multiplying with (wt) from (PLL) is shown in Fig 7c to show the results.

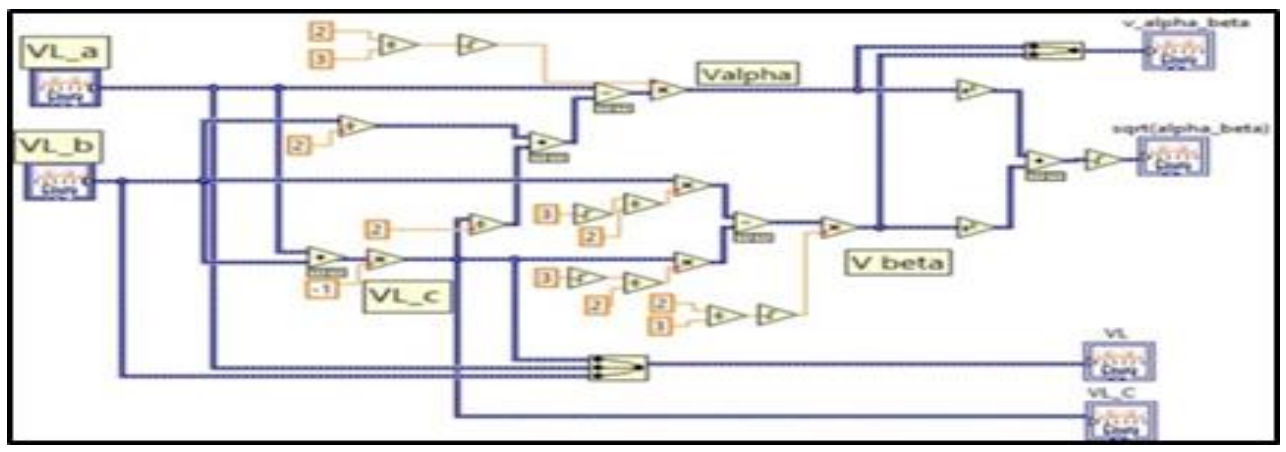

(a) 


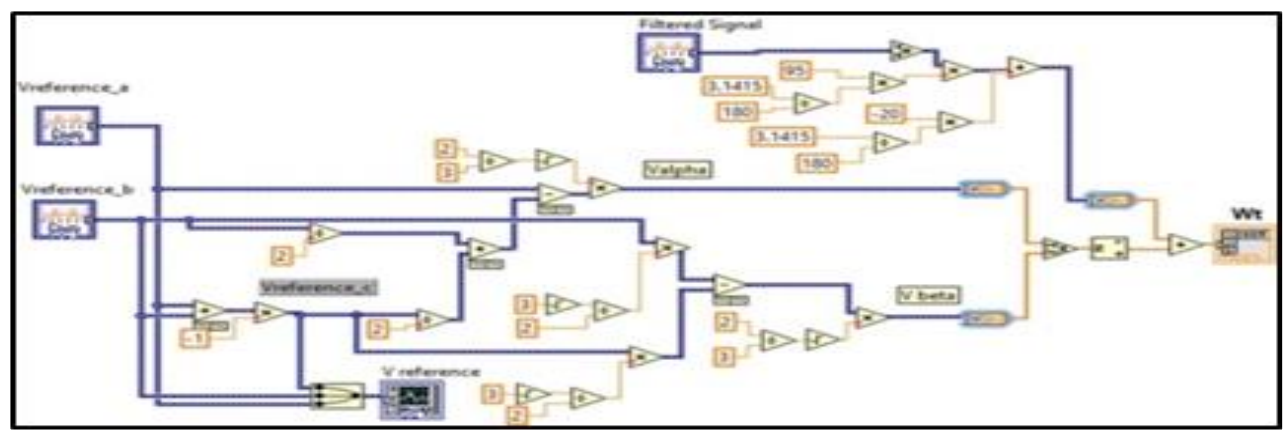

(b)

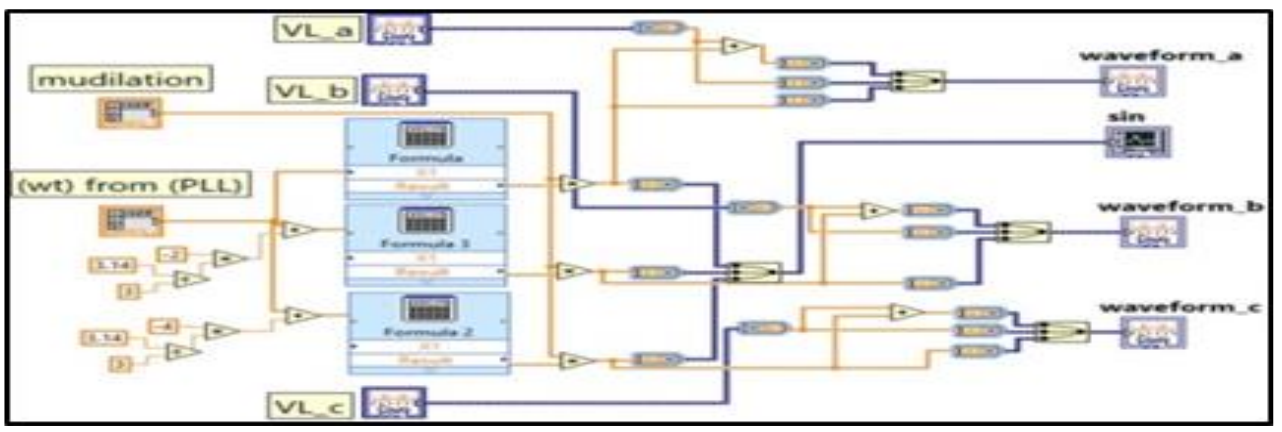

(c)

Fig 7. (a) Clark transformation structure. (b) structure of phased-locked loop (PLL). (c) Block diagram of results.

The data acquisition card (DAQ) is utilized to collect data from (voltage sensors) and then use this data as feedback for the control circuit. The data acquisition used in this paper is (Ni USB6009) [25]. Fig 8 shows the signal description of DAQ and illustrates the inputs signals used from voltage sensors

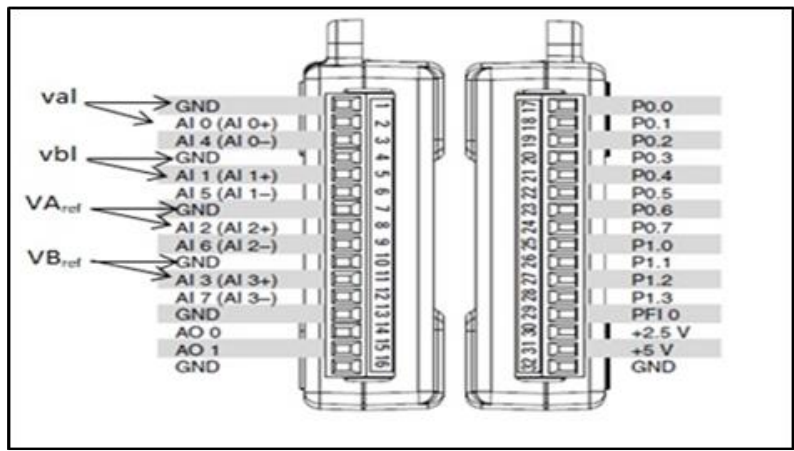

Fig 8. Signal description of DAQ. 
The procedure of prototyping the laboratory model is shown in Fig 5. starting with the nominal operating condition. At this condition, the load is only a sensitive load, represented by (RL1 and RL2). At the Nominal value condition in system voltage, the switch (SW1) is open, and the switch (SW2) is closed as shown in Fig 9a. The value of the output controller at nominal condition, a value resulted from a comparison between the reference voltage with aggregate voltage, is close to zero, as shown in Fig 9b. When SW1 is closed, the loads (RL3, RL4) are added in parallel with the sensitive loads. In this case, the nominal value is decreased by a certain percentage to make sag condition. In this case, the output control unit value increases from the zero value to achieve the value of the injected voltages it acts as compensation for the lower voltage value on the loads. When (sw1) and (sw2) are open, the load is only RL1. The nominal value is increasing by a certain percentage to make the swell voltage condition. The value of the output controller in this condition decreasing from zero to achieve the value of opposite injected voltages that act as compensation for the value of the swell voltage on the load.

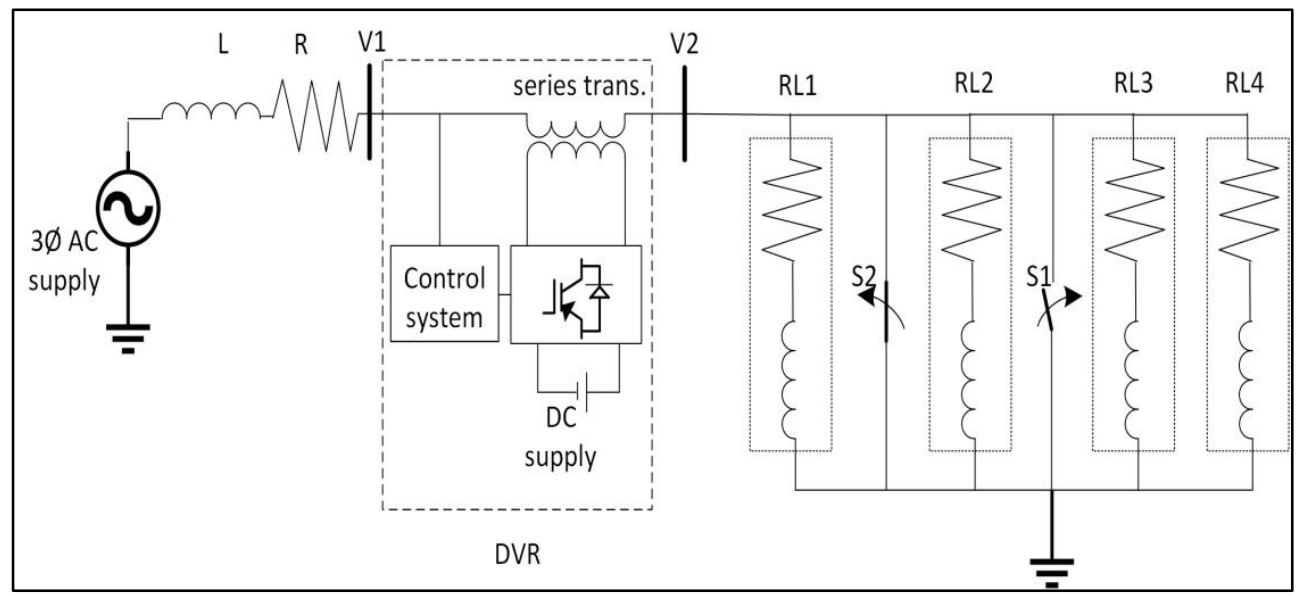

(a)

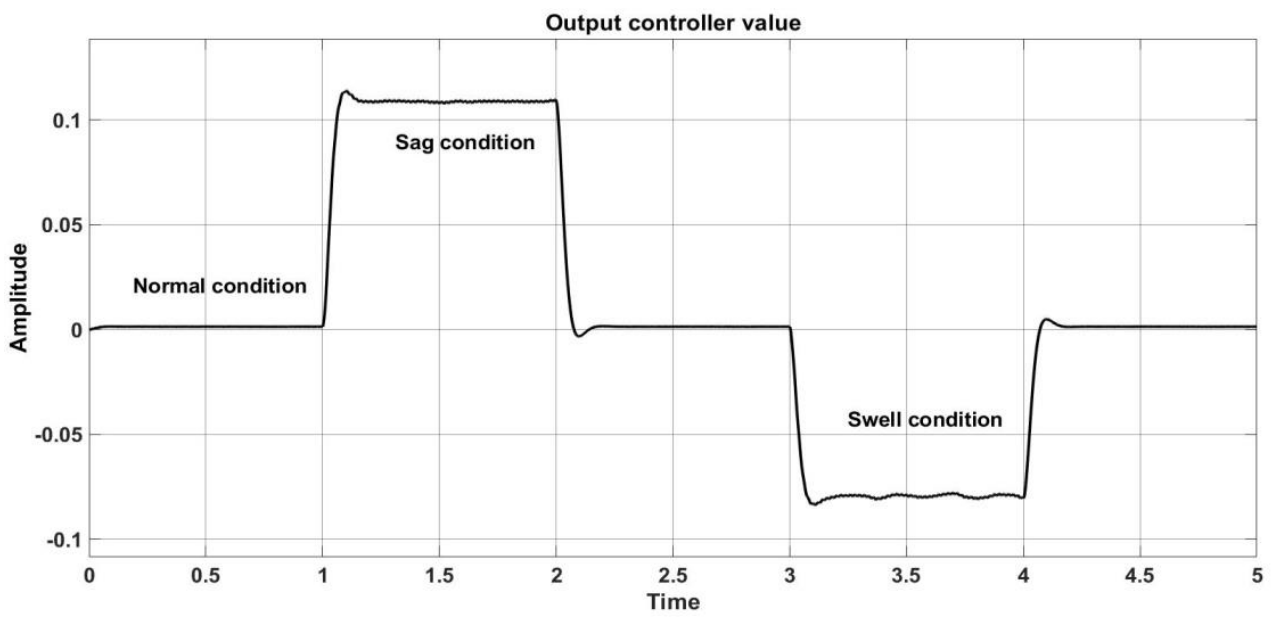

(b) 
Fig 9. (a) ) Experimental setup for DVR. (b) The value of output controller.

The proposed work is carried out by several cases:

Case1 (Normal condition): The circuit is equipped with a three-phase power supply with a voltage of $20 \mathrm{~V}$ as shown in Fig 10. the injection wave represented by the green line is equal to zero, meaning there is no injection.

Case2 (Sag condition): In this case, during the Normal operation, sudden loads are added to the sensitive loads (RL3, RL4). Decrease of $12.5 \%$ in the voltage at the ends of the load to $17.5 \mathrm{~V}$. During this instantaneous dwindling, a compensating voltage will be injected from the inverter is shown in Fig 11. The sine wave represented in the red line is the Sag wave. Also, the sine wave represented in the green line is the injection magnitude wave whose value is $2 \mathrm{~V}$. Finally, the sine wave represented in black is the sum of the Sag wave and the injection wave. Case 3 (Swell condition): In this case, it is a sudden departure from sensitive loads (the only load is RL1). An increase of $10 \%$ in the voltage at the end of this load to $22 \mathrm{~V}$. As shown in Fig 12 , the sine wave represented in red is the $\mathrm{L}$ wave. The sine wave represented in green is the injection wave, which is opposite to the increasing wave. The sine wave represented in black is the product of the sum of the previous two waves.

The response of injected voltage in (Sag and Swell) cases (with/without) PI controller obtained in Fig 13.

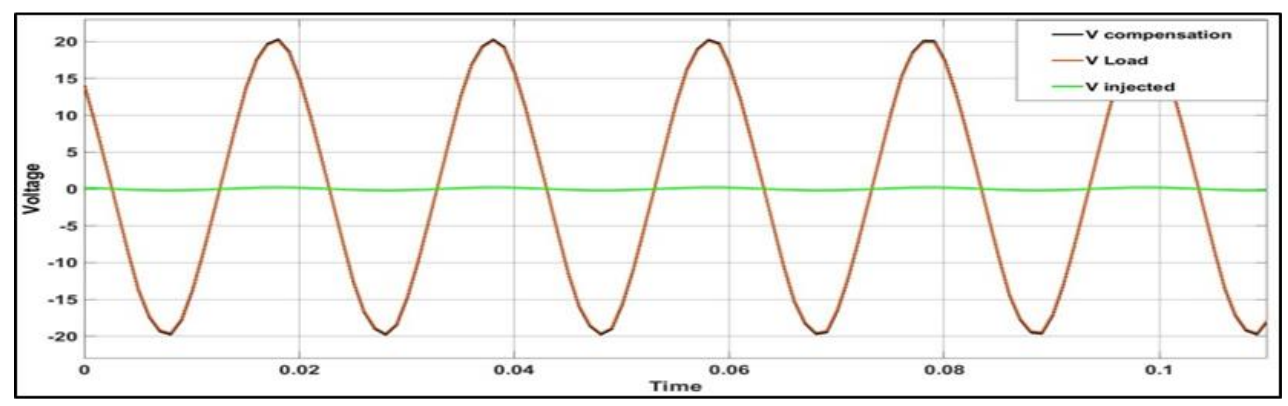

Fig 10. The waveform at Normal condition.

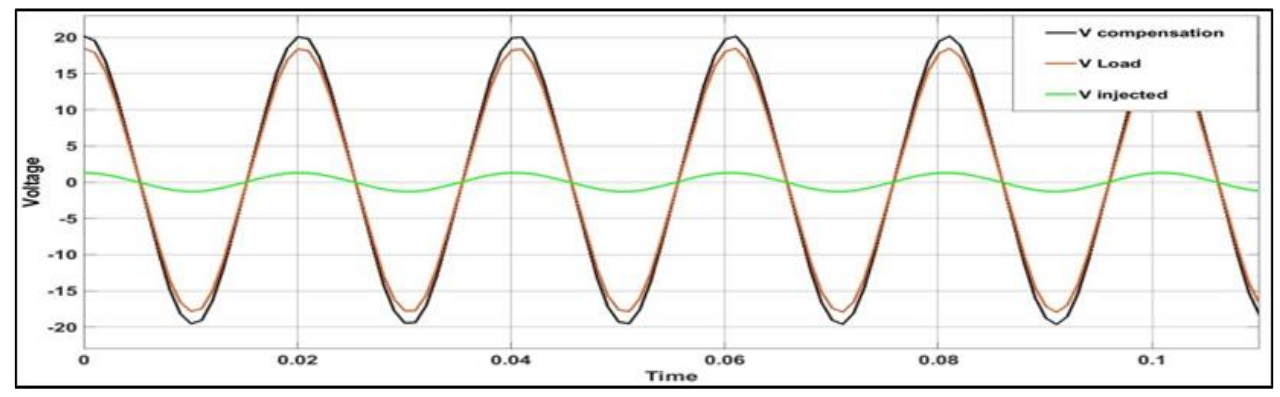

Fig 11. The waveform at Sag condition 


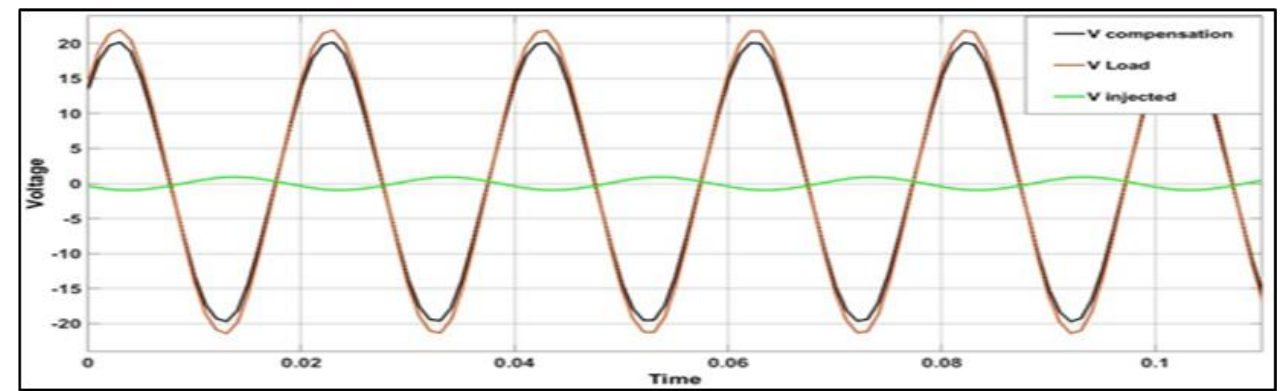

Fig 12. The waveform at Swell condition

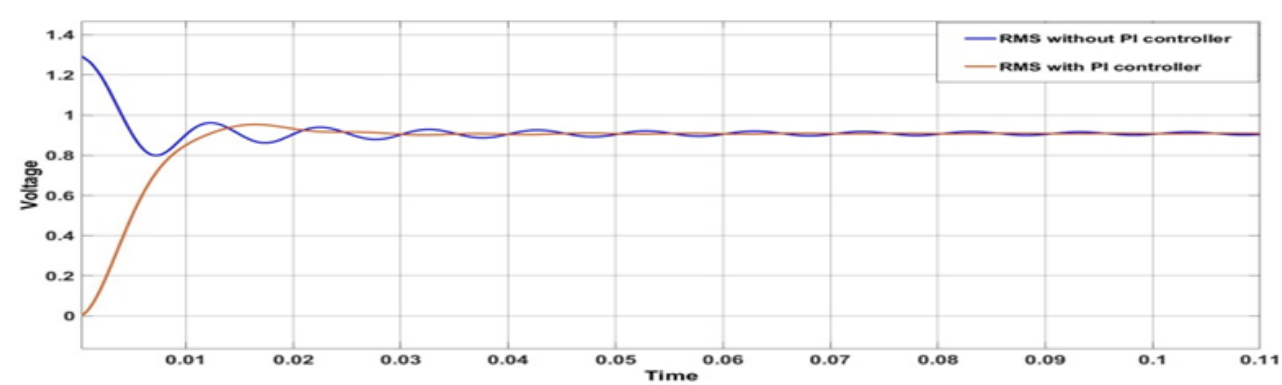

Fig 13. RMS value (with/without) PI controller.

\section{Conclusion}

In this paper, dynamic voltage restorer (DVR) performance is presented to instantaneously reduce sag and swell in voltages, which is one of the power quality problems on sensitive loads. PQ theory is used to control the amount of injected and compensated voltages. Compensation of $10 \%$ of the total value of sag $(12.5 \%)$ obtained in the system. The swelling compensation rate is $8 \%$ of the total value of swelling $(10 \%)$ in the system. The future work is now preparing to obtain compensated voltage for dip voltage conditions and upgrade the controller to utilize adaptive controller like adaptive Neuro-Fuzzy system.

\section{Appendix}

In prototype model:

a- All loads used in the prototype have equal values

$\mathrm{R}=140 \Omega, \mathrm{L}=471 \mathrm{mH}$.

b- Voltage Detection Sensor Module 25v [26]. 


\section{Acknowledgments}

We would like to express our appreciation to the staff of the power system and machines laboratory, in the Technical Engineering College/Mosul, for their help and support to make the required tests and measurements.

\section{References}

[1] M.T .Alkhayyat Mahmood, and Sinan M. Bashi. "Mitigation Unbalance Nonlinear Loads and Dissimilar Line Currents Using Shunt Active Power Filter SAPF." International Journal of Advanced Engineering, Management and Science 2.10: 239666.

[2] N. L. Ismail, H. D. M. Hidzir, S. Thanakodi, N. S. M. Nazar, P. Ibrahim, and C. K. M. S. C. K. Ali, "Modeling voltage sag mitigation using dynamic voltage restorer and analyzing power quality issue," AIP Conf. Proc., vol. 1930, no. February, 2018, doi: 10.1063/1.5022921.

[3] Van Minh, N., Khanh, B. Q., and Phuong, P. V. (2017, July). Comparative simulation results of DVR and D-STATCOM to improve voltage quality in distributed power system. In 2017 International Conference on System Science and Engineering (ICSSE) (pp. 196-199). IEEE.

[4] Abas, N., Dilshad, S., Khalid, A., Saleem, M. S., and Khan, N. , " Power Quality Improvement Using Dynamic Voltage Restorer". IEEE Access, vol .8,pp.164325164339, doi:10.1109/access.2020.3022477,(2020).

[5] Edomah, Norbert. " Effects of voltage sags, swell and other disturbances on electrical equipment and their economic implications" , IEEE Proc. of 20th International Conference on Electricity Distribution, p. 1-4, doi: 10.1049/cp.2009.0502,2009.

[6] DASGUPTA, Anindya; SENSARMA, Parthasarathi. "Voltage Sag Mitigation", Springer Singapore, pp. 91-106,doi: 10.1007/978-981-10-3831,2017.

[7] Mohammed Y. Suliman and Mahmood T. Al-Khayyat. "Power flow control in parallel transmission lines based on UPFC." Bulletin of Electrical Engineering and Informatics 9.5 (2020), pp.1755-1765.

[8] Pradhan, M., and Mishra, M. K. (2018). Dual P-Q Theory based Energy Optimized Dynamic Voltage Restorer for Power Quality Improvement in Distribution System. IEEE Transactions on Industrial Electronics, 1-1. doi:10.1109/tie.2018.2850009

[9] Ital, A. V., and Borakhade, S. A.," Compensation of voltage sags and swells by using Dynamic Voltage Restorer (DVR)",2016 International Conference on Electrical, Electronics, and Optimization Techniques (ICEEOT), doi:10.1109/iceeot.2016.7754936,(2016).

[10] Singh, S. K., and Srivastava, S. K. "Enhancement in power quality using dynamic voltage restorer (DVR) in distribution network", 2017 International Conference on Innovations in Information, Embedded and Communication Systems (ICIIECS) , doi: 10.1109/ICIIECS.2017.8275918,pp. 1-5, (2017, March).

[11] Shraddha, B., R, S., Pillai, S. J.and Modi, S. ,"Simulation and Analysis of Dynamic Voltage Restorer", 2018 3rd IEEE International Conference on Recent Trends in Electronics, Information \& Communication Technology (RTEICT). doi:10.1109/rteict42901.2018.9012532, (2018).

[12] Rahman, S. A., et al. "A Novel DVR Topology to Compensate Voltage Swell, Sag, and Single-Phase Outage." Iranian Journal of Electrical and Electronic Engineering 17.4 (2021) , pp. 2036-2036.

[13] Venugopal, S. and Agarwal, V. A," novel control strategy for an ultra-capacitor based dynamic voltage restorer with controllable dc-link voltage", 2015 IEEE 6th International Symposium on Power Electronics for Distributed Generation Systems (PEDG) , pp. 1-7, IEEE, (2015, June).

[14] El Sayed, N. G., El-Saady, G., Ibrahim, E. N. A. and Mohamed, M. A.," Dynamic Voltage Restorer for Enhancing Distribution Systems Power Quality", 2019 7th International Japan-Africa Conference on Electronics, Communications, and Computations,(JAC-ECC),pp. 210-215, IEEE, (2019, December).

[15] Mohammed Y.Suliman and Sameer Sadoon Al-Juboori ,"Design of Fast Real Time Controller for the Dynamic Voltage Restorer Based on Instantaneous Power Theory." International Journal of Energy and Power Engineering 5.2-1, doi: 10.11648/j.ijepe.s.2016050201.11 ,pp. 1-6 , 2016. 
[16] S. S. Sananse and M. Alkathakur, "Dynamic Voltage Restorer ( DVR ) Through MATLAB Simulation," pp. 184-190, 2015.

[17] Tashackori, A., Hosseini, S. H., Sabahi, M. and Nouri T. A,"Three-phase four-leg DVR using three dimensional space vector modulation", In 201321 st Iranian conference on electrical engineering (ICEE) , pp. 1-5 , doi: 10.1109/IranianCEE.2013.6599761 , 2013, May.

[18] Kakar, F., bin Mohd Zin, A. A. and Bin Habibuddin, M. H. ,"Performance of PI Controller Based Dynamic Voltage Restorer for Power Quality Improvement.", In Applied Mechanics and Materials ,Vol. 818, pp. 52-57, Trans Tech Publications Ltd. (2016)

[19] M. Y. Suliman, "Voltage profile enhancement in distribution network using static synchronous compensator STATCOM," International Journal of Electrical and Computer Engineering (IJECE), 2020, vol. 10 , no. 4 , pp. 3367-3374.

[20] Akagi, H., Watanabe, E. H. and Aredes M. ,"Instantaneous power theory and applications to power conditioning". John Wiley \& Sons.,(2017).

[21] Katole, D. N., Daigavane, M. B., Gawande, S. P. And Daigavane, P. M." Vector based analysis for design of single phase SRF controller in Dynamic Voltage Restorer". IEEE International Conference on Power Electronics, Drives and Energy Systems (PEDES). 2018,doi:10.1109/pedes.2018.8707774.

[22] M. Y. Suliman,. and Bashi S. M. "Fast response SSSC based on instantaneous power theory." In 2013 International Conference on Electrical Communication, Computer, Power, and Control Engineering (ICECCPCE) , pp. 174-178, IEEE. (2013, December).

[23] A. Mohamed Eltamaly, Y. Sayed Mohamed, A. H. Mustafa El-Sayed, and A. N. Abd Elghaffar, "Enhancement of Power System Quality Using PI Control Technique with DVR for Mitigation Voltage Sag," 2018 20th Int. Middle East Power Syst. Conf. MEPCON 2018 - Proc., pp. 116-121, 2019, doi: 10.1109/MEPCON.2018.8635221.

[24] National-Instruments, "LabVIEW User Manual - Getting Started with LabVIEW," no. June, p. 349, 2013, .

[25] National Instrument Team, “User Guide Ni Usb-6008/6009.” pp.1-26,2015,: $\mathrm{pdf} / \mathrm{manuals} / 371303 \mathrm{n}$.pdf.

[26] S. G. Technology, "Model : Voltage Sensor / 170640 Reference Code :," no. 1000. p. 170640, 2015. 